Tropical Journal of Pharmaceutical Research June 2017; 16 (6): 1267-1275

ISSN: $1596-5996$ (print); 1596-9827 (electronic)

(C) Pharmacotherapy Group, Faculty of Pharmacy, University of Benin, Benin City, 300001 Nigeria.

All rights reserved.

Available online at http://www.tjpr.org

Original Research Article

http://dx.doi.org/10.4314/tjpr.v16i6.9

\title{
A new and efficient method for purification of poly- $y-$ glutamic acid from high-viscosity fermentation broth
}

\author{
Fengqing Wang ${ }^{1 *}$, Jinzhong Liang ${ }^{2}$, Wei Wang ${ }^{2}$, Dawei $\mathrm{Fu}^{2}$ and Wei Xiao ${ }^{2}$ \\ ${ }^{1}$ Department of Biological Engineering, Sichuan University of Science and Engineering, Zigong City, Sichuan 643000, PR \\ China, ${ }^{2}$ College of Food Engineering, Harbin University of Commerce, Harbin City, Heilongjiang 150076, PR China
}

${ }^{\star}$ For correspondence: Email: wangfengqing_100@126.com

Sent for review: 22 February 2017

Revised accepted: 24 May 2017

\begin{abstract}
Purpose: To devise an efficient strategy for the separation and recovery of high-quality $\gamma$-PGA by investigation of the physical properties, pigment properties and microfiltration mode of high-viscosity fermentation broth

Methods: The bacterial strain, Bacillus subtilis 115, was used in this study. The viscosity of the fermentation broth was determined by digital viscometer with spindle SP-2 at $25^{\circ} \mathrm{C}$. The concentrations of glucose and L-glutamate were analyzed with a biosensor equipped with both glucose oxidase and Lglutamate oxidase electrodes. The pigment in the fermentation liquid was scanned with a UV spectrophotometer at wavelength range of $200-500 \mathrm{~nm}$ and was removed using activated carbon. Measurement of IR spectrum was performed using an IR spectrophotometer with KBr pellet. .

Results: The results showed that the $\gamma$-PGA yield was $35 \mathrm{~g} / \mathrm{L}$. The viscosity of the fermentation broth was $1600 \mathrm{mPa}$.s at the end of the batch fermentation. After 3-fold dilution, the viscosity was reduced to one-fortieth of the original value at $65^{\circ} \mathrm{C}$ for $30 \mathrm{~min}$., which allowed effective removal of Bacillus subtilis 115 from the broth. Maximum UV absorption of the pigment was occurred at $260 \mathrm{~nm}$. The pigment was removed by shaking with $0.6 \%$ activated carbon powder at $50 \mathrm{rpm}$ for $20 \mathrm{~min}$, resulting in $88 \%$ decolorization. Concentration with hollow-fiber membrane (MWCO 500,000) resulted in complete removal of residual glucose and glutamic acid from the aqueous solution of $\gamma$-PGA. The molecular weight of the $\gamma$-PGA was $1095 \mathrm{kDa}$, and its UV scanning spectrum showed an absorption peak at $216 \mathrm{~nm}$. The decomposition temperature (Td) of the $y$-PGA was 312.92 oC. Its IR spectrum was consistent with the presence of carboxyl, hydroxyl, carbonyl and amide groups.

Conclusion: An efficient method for the extraction and purification of high-quality $\gamma$-PGA from highviscosity fermentation broth.
\end{abstract}

Keywords: Bacillus subtilis 115, v-Polyglutamic acid, De-pigmentation, Activated carbon, Ultra-filtration, High-viscosity fermentation broth

Tropical Journal of Pharmaceutical Research is indexed by Science Citation Index (SciSearch), Scopus, International Pharmaceutical Abstract, Chemical Abstracts, Embase, Index Copernicus, EBSCO, African Index Medicus, JournalSeek, Journal Citation Reports/Science Edition, Directory of Open Access Journals (DOAJ), African Journal Online, Bioline International, Open-J-Gate and Pharmacy Abstracts

\section{INTRODUCTION}

$\mathrm{Y}$ - Polyglutamic acid ( $\mathrm{Y}$ - PGA), a homo polyamide of $\mathrm{D}$ - and L-glutamic acid units, was first discovered as a component of capsules of Bacillus anthracis by Ivonovics and Bruckner [1]. It contains linkages between $\alpha-$ amino and $y$ carboxylic groups, as opposed to peptide bonds in proteins. Consequently, $\mathrm{y}-\mathrm{PGA}$ is resistant to proteases [2]. However, the polymer is environmentally friendly, nontoxic and non immunogenic, and can therefore be used safely in a variety of rapidly increasing applications. Because of these potential applications, the development of processes for improved production and recovery of $\mathrm{y}$-PGA from the 
fermentation broth is great importance. However, most research on microbial production of $Y$ - PGA are focused on screening of strains, the optimization of medium and culture conditions with the potential to produce high yield, specific enantiomeric composition and desired molecular mass of $y$ - PGA at reduced cost. There have been few researchs on the extraction and purification of $y$ - PGA from fermentation broth.

$Y$ - PGA can be synthesized by polymerase on microbial cell membranes, and then excreted into the culture medium. The molecular weight of $Y$ PGA is high, and varies from 100 to $2000 \mathrm{kDa}$. Thus the fermentation liquid becomes highly viscous on production of $Y$ - PGA. Cells encapsulated with $Y$ - PGA possess negative charges near neutral $\mathrm{pH}$ because of the ionization of carboxyl groups in $\mathrm{Y}$ - PGA molecules. The negative surface charges confer high stability on Y - PGA - encapsulated cells in the culture broth. The stability and high viscosity of the broth create difficulties in sedimentation of the cells during the separation process [2]. This is a major concern in the separation of the cells from $y$ - PGA in the culture broth.

This study was aimed at finding a feasible method of the separation and recovery of high quality $Y$ - PGA, through investigation of the physical properties, pigment properties and microfiltration mode of the high - viscosity fermentation broth.

\section{EXPERIMENTAL}

\section{Materials}

Granular and powdered, activated carbon were purchased from Xilong Chemical Limited. The activated carbon granules were sieved through number 30 screen to remove fine carbon powder. The portion of activated carbon granules retained on the screen was washed three times with excess volume of $70 \%$ aqueous ethanol to remove any powdered carbon adhering to the surface of the carbon granules. After evaporation of the ethanol, the washed granules were dried overnight in a hot air oven at $105^{\circ} \mathrm{C}$.

\section{Preparation of corn saccharification liquid}

Saccharification of corn starch was catalyzed by the double-enzyme method. In this process, a $1: 3$ (w:v) mixture of corn powder and water (in a tank) was liquefied at $85^{\circ} \mathrm{C}$ for $30 \mathrm{~min}$ at $\mathrm{pH} 6.7$ 7.0 using commercial thermo - stable $\alpha$ amylase $(20 \mathrm{KU} / \mathrm{g})$. The temperature of the corn saccharification liquid was rapidly decreased to about $60^{\circ} \mathrm{C}$, and then the $\mathrm{pH}$ was adjusted to 4.5 with hydrochloric acid. Release of monosaccharides from the saccharification liquid was catalyzed by commercial glucoamylase (50 $\mathrm{KU} / \mathrm{g}$ ) for $4 \mathrm{~h}$. The main components of the corn hydrolysate were reducing sugars, cellulose, and protein (70:11:4 on weight basis). After presaccharification, the glucose monomer fraction was close to $25 \%$, and the level of release of glucose and nutrients (including protein) was a function of saccharification time. Complete starch hydrolysis required more than $7 \mathrm{~h}$ of pre saccharification.

\section{Strain and fermentation}

The bacterial strain used in this study was Bacillus subtilis 115. Batch cultures of Bacillus subtilis 115 were carried out in a $30-\mathrm{L}$ jar fermentor containing $20 \mathrm{~L}$ of medium at $37^{\circ} \mathrm{C}$ and $150 \mathrm{rpm}$ for $72 \mathrm{~h}$. The medium contained (per liter) $250 \mathrm{~mL}$ of corn saccharification liquid (sugar concentration: $200 \mathrm{~g} / \mathrm{L}$ ), $\mathrm{CaCl}_{2}(0.42 \mathrm{~g}$ ), peptone $(4 \mathrm{~g})$, monosodium glutamate $(50 \mathrm{~g})$, $\mathrm{NaCl}(12 \mathrm{~g}), \mathrm{MgSO}_{4} \cdot 7 \mathrm{H}_{2} \mathrm{O}(1.25 \mathrm{~g}), \mathrm{KH}_{2} \mathrm{PO}_{4}(4 \mathrm{~g})$ and $\mathrm{MnSO}_{4}(0.08 \mathrm{~g})$.

\section{Analytical procedures}

After separation of the cells by centrifugation, the concentration of glucose and L - glutamate remaining in the medium were determined by a biosensor analyzer with both glucose oxidase and L - glutamate oxidase electrodes (Institute of Biology, Shandong Academy of Sciences SBA 40D). The viscosity of the culture broth was measured by Digital Viscometer with spindle SP2 at $25{ }^{\circ} \mathrm{C}$ (DNJ - 5S, China). Infrared spectrometer was used to analyze the absorption characteristics of the samples with $\mathrm{KBr}$ pellet (Nicolet - Magna - IR 550, USA).

\section{Removal of pigment in fermentation liquid}

Dried activated carbon powder and granules $(0.2,0.4,0.6,0.8$ and $1.0 \mathrm{~g})$ were separately measured into six $250 \mathrm{~mL}$ Erlenmeyer flasks. A flask without activated carbon served as negative control. The cell-free fermentation liquid $(100 \mathrm{~mL})$ was added to each flask and the flasks were then sealed with parafilm. The decolorization process was carried out on an Incubator Shaker at 50rpm. The UV absorbance of each liquid fraction was measured at $260 \mathrm{~nm}$.

\section{Statistical analysis}

The data are presented as mean \pm standard deviation were analyzed Student t-test with Microsoft Excel 2003. $P<0.05$ was considered statistically significant. 


\section{RESULTS}

\section{Batch fermentation produced $y$-PGA}

$\mathrm{Y}$ - PGA was produced in a $30 \mathrm{~L}$ stirred tank bioreactor under the following conditions: stirring speed of $150 \mathrm{rpm}$, ventilation rate of $1.6 \mathrm{~m}^{3} / \mathrm{h}$, tank pressure of $0.08 \mathrm{MPa}$, and culture temperatures between 36.5 and $37.5{ }^{\circ} \mathrm{C}$. The yields of $y$ - PGA as a function of changes in broth nutrient composition with time are shown in Figure 1. Changes in the $\mathrm{pH}$ of the fermentation broth were also monitored, and the results are shown in Figure 2. Although $\mathrm{pH}$ played an important role in the production of $\mathrm{Y}$ - PGA by Bacillus subtilis 115, results from the experiments in this study indicated that strict control of $\mathrm{pH}$ was not necessary. In the fermentation, monosodium glutamate was a carbon source for $\mathbf{y}$ - PGA formation, while the glucose in the corn saccharification liquid served as source of energy for microbial growth and product formation. As shown in Figure 1, the concentration of glucose in the bioreactor rapidly decreased after $10 \mathrm{~h}$. At this time, the release of
$\mathbf{Y}$ - PGA into the broth had commenced. This implies that the production of $\mathbf{Y}$ - PGA was partially associated with cell growth. The levels of consumption of glutamate and glucose during the fermentation process were about $10 \mathrm{~g} / \mathrm{L}$ and 60 $\mathrm{g} / \mathrm{L}$, respectively, and the yield of $\mathrm{Y}$ - PGA was stable, rising to a peak value of $35 \mathrm{~g} / \mathrm{L}$.

\section{Effect of temperature on viscosity of fermentation broth at different dilution time}

The viscosity of $\mathrm{y}$ - PGA fermentation liquid was too high, it was not conducive to the removal of the cell. Accordingly, the effect of temperature on the viscosity of fermentation broth with different dilution times was evaluated. As shown in Figure 3 , the viscosity of the culture broth decreased with increasing temperature and degree of dilution (dilution - fold). When the fermentation liquid was diluted 3-fold, the viscosity reduced from 1600 to $100 \mathrm{mPa} . \mathrm{s}(6.25 \%$ of initial viscosity) at $35{ }^{\circ} \mathrm{C}$, and eventually fell to 20 $\mathrm{mPa}$.s following a 5 - fold dilution at $65^{\circ} \mathrm{C}$ for 10 $\min$.

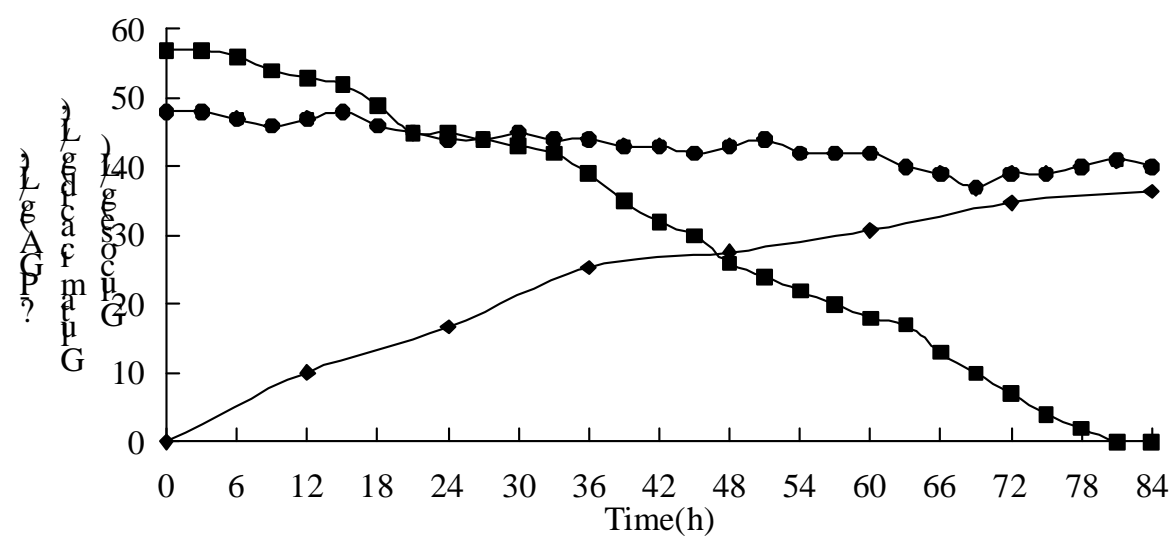

Figure 1: Yield of $Y$ - PGA, concentration of glucose and glutamic acid as function of changes in broth nutrient composition with time. Note: - means the curve of $y$ - PGA production with time. - means the curve of glucose consumption with time. means the curve of glutamic acid consumption with time

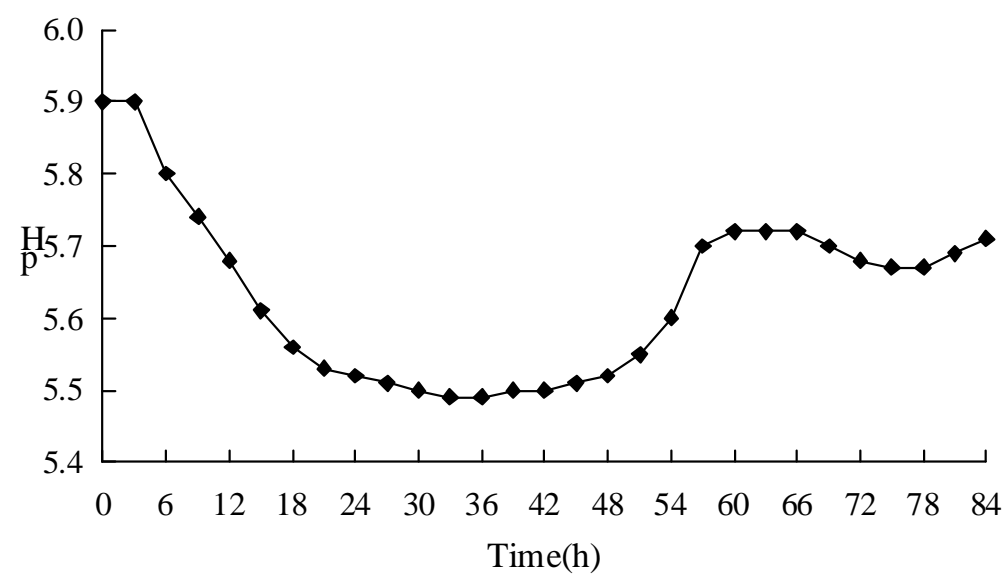

Figure 2: Changes in $\mathrm{pH}$ of the fermentation broth with time 

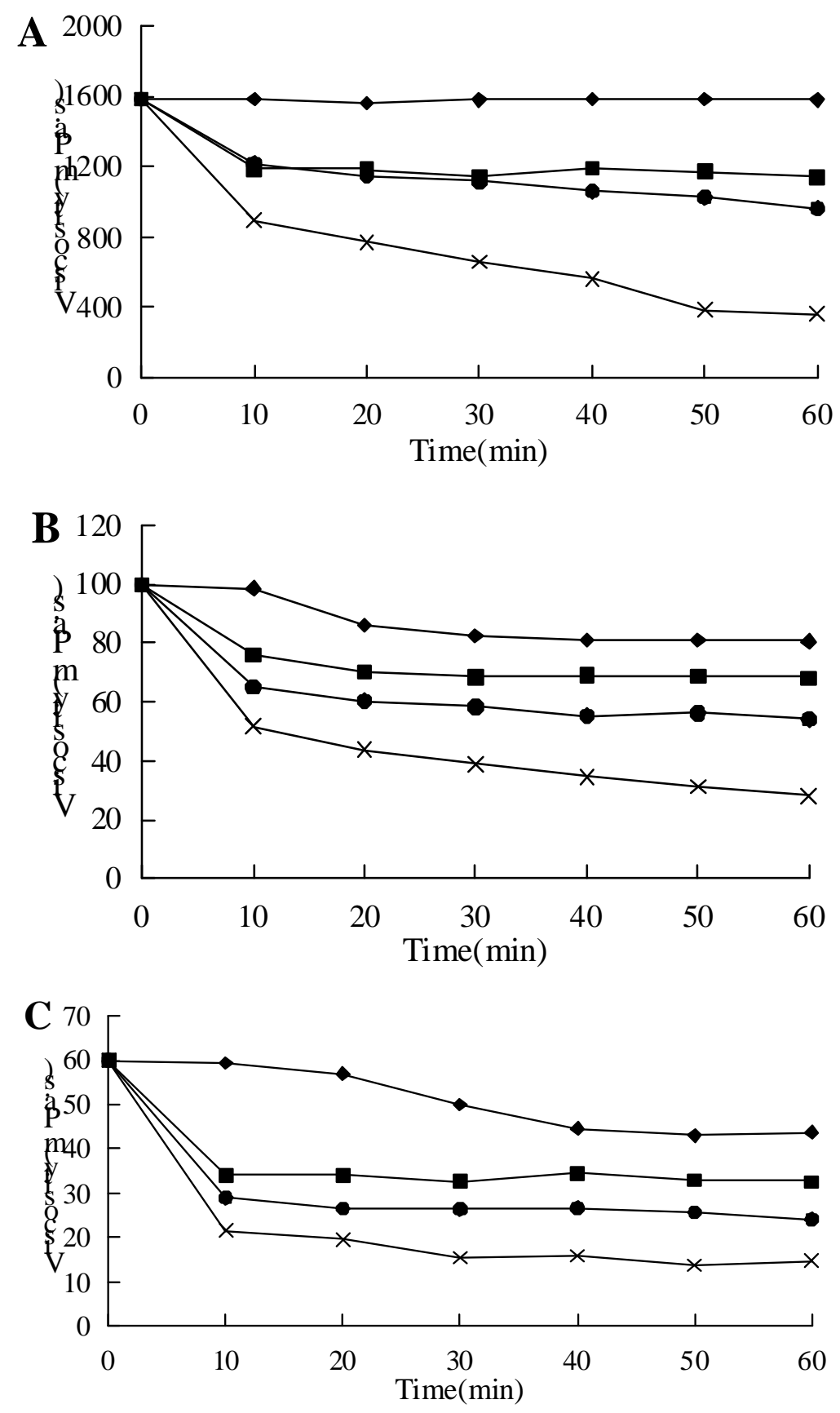

Figure 3: Effect of temperature and dilution on broth viscosity. Culture broth diluted 2-fold (A); culture broth diluted 3-fold (B); culture broth diluted 5-fold (C). Note: $\bullet=$ fermentation broth was treated at $35^{\circ} \mathrm{C}$; $\square=$ fermentation broth was treated at $45^{\circ} \mathrm{C} ; \bullet=$ fermentation broth was treated at $55{ }^{\circ} \mathrm{C} . \times=$ fermentation broth was treated at $65^{\circ} \mathrm{C}$

\section{Effect of pH on the viscosity of fermentation broth at different dilution times}

The viscosity of the fermentation broth containing $Y$ - PGA is not only affected by temperature, but also affected by $\mathrm{pH}$. The $\mathrm{pH}$ of the culture broth was adjusted to $2.5-11.5$ with $6 \mathrm{~mol} / \mathrm{L} \mathrm{HCl}$ and $10 \mathrm{~mol} / \mathrm{L} \mathrm{NaOH}$. The effect of temperature on the viscosity of fermentation broth with different dilution times was evaluated. Figure 4 shows that the viscosity of fermentation broth was affected by $\mathrm{pH}$ and dilution fold. At the end of fermentation, the $\mathrm{pH}$ of the culture broth was about 5.5. As shown in Figure 4, the viscosity of fermentation broth significantly decreased as the $\mathrm{pH}$ decreased from 5.5 to 2.5 and increased from 8.5 to 11.5 with dilution 1 fold.

\section{Characteristics of pigment in fermentation liquid}

The fermentation liquor, prior to removal of cells 


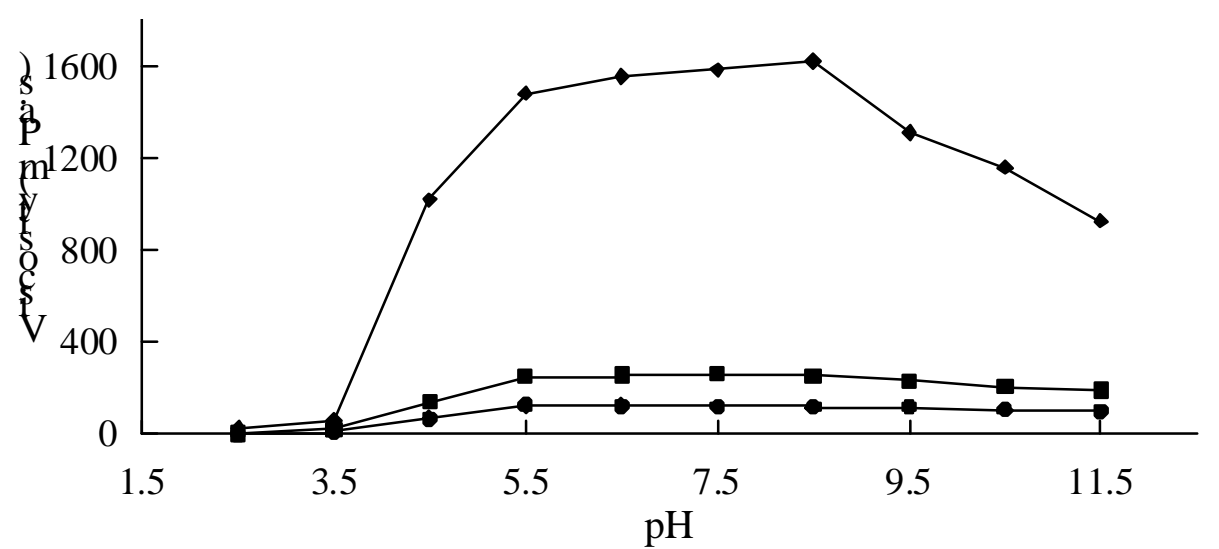

Figure 4: Effect of $\mathrm{pH}$ and dilution on broth viscosity. NOTE: $\bullet=$ dilution 1 -fold. $\boldsymbol{a}=$ dilution 2 -fold. $\bullet=$ dilution 3-fold

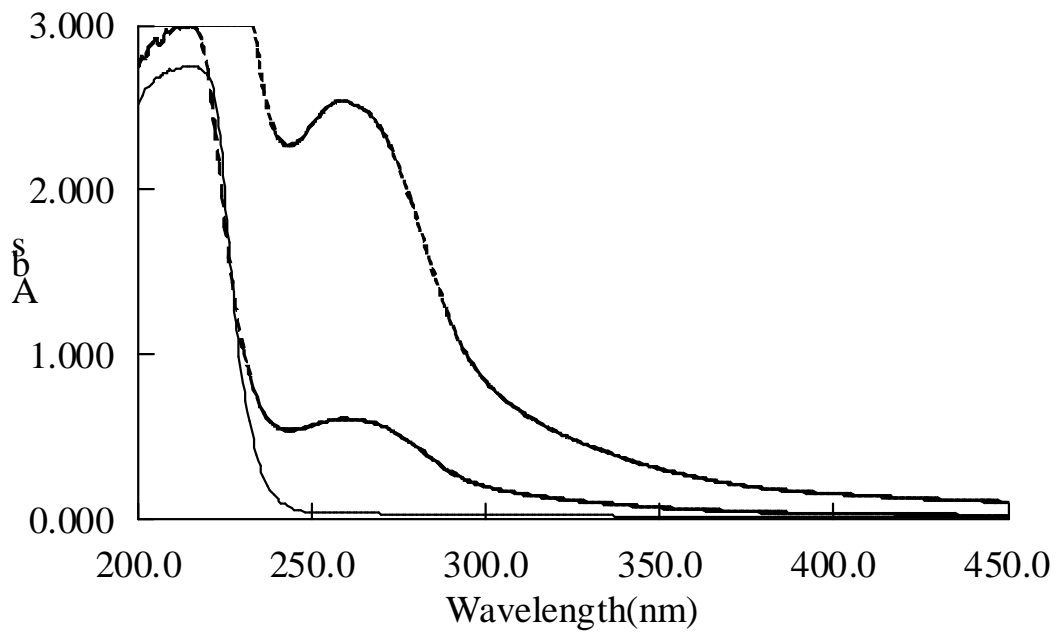

Figure 5: Spectral analysis of the culture broth (treated and untreated with activated carbon), and high purity $\gamma^{-}$ PGA over wavelength range of 200 to $500 \mathrm{~nm}$. Note: From top to bottom, the curves represent treated and untreated with activated carbon, high purity $\mathrm{Y}$-PGA.

by plate-and-frame filtration, was buff due to pigment. This would affect the quality of $y$ - PGA products. Thus experiments were carried out to determine the characteristics of the pigment and the most efficient decolorization method to be used. The sample was scanned in a UV spectrophotometer at wavelength range of 200 $500 \mathrm{~nm}$. As shown in Figure 5, it was found (through comparison with the spectrum of highpurity $\mathrm{Y}$ - PGA) that the maximum absorption wavelength of the pigment in the fermentation liquor was $260 \mathrm{~nm}$.

\section{Effect of activated carbon powder and granules on pigment removal}

The results indicated that activated carbon was very effective in removal of the pigment. As shown in Figure 6A, the decolorization effect of powdered activated carbon was better than that of granulated activated carbon. The results revealed that under the experimental conditions used (shaking at $50 \mathrm{rpm}$ for $20 \mathrm{~min}$ ), $0.6 \%$ powdered activated carbon was the most effective concentration for decolorization and removal of impurities from the cell-free culture broth containing $y$-PGA.

Activated carbon is a non-specific adsorbent which decolorizes by binding to colored components/pigments. The advantage of this method of decolorization is that due to its high molecular weight, $\mathrm{Y}$ - PGA does not adsorb readily to activated carbon, unlike low molecular impurities, such as pigments and proteins. The percentage decolorization which is the ratio of the absorbance values at $260 \mathrm{~nm}$ before and after decolorization, was up to $88 \%$ as shown in Figure $6(\mathrm{~B})$. The rate of decolorization remained constant with changes in duration of shaking.

\section{Concentration of $\mathrm{Y}-\mathrm{PGA}$ aqueous solution by ultra-filtration}

The use of concentrated solutions of $y$ - PGA reduces cost of drying. Ultra - filtration is typically 
used to concentrate solutions of macromolecules and colloids from solution, the lower limit being solutes with molecular weights of a few thousand Daltons. Because of high molecular weight, $Y$ PGA aqueous solution could also be concentrated by ultra - filtration. After fermentation the molecular weight of $\gamma$ - PGA was in the range of $500-1200 \mathrm{kDa}$. Therefore, a membrane having Molecular Weight Cut Off (MWCO) of $100 \mathrm{kDa}$ was chosen as an efficient and economical procedure for concentration of $\gamma$ - PGA. The $y$ - PGA solution was concentrated at a pressure of $0.12 \mathrm{MPa}$ using the concentration dilution - concentration - dilution - concentration method, with a hollow - fiber cartridge having a membrane area of $650 \mathrm{~cm}^{2}$, as shown in Table 1 .
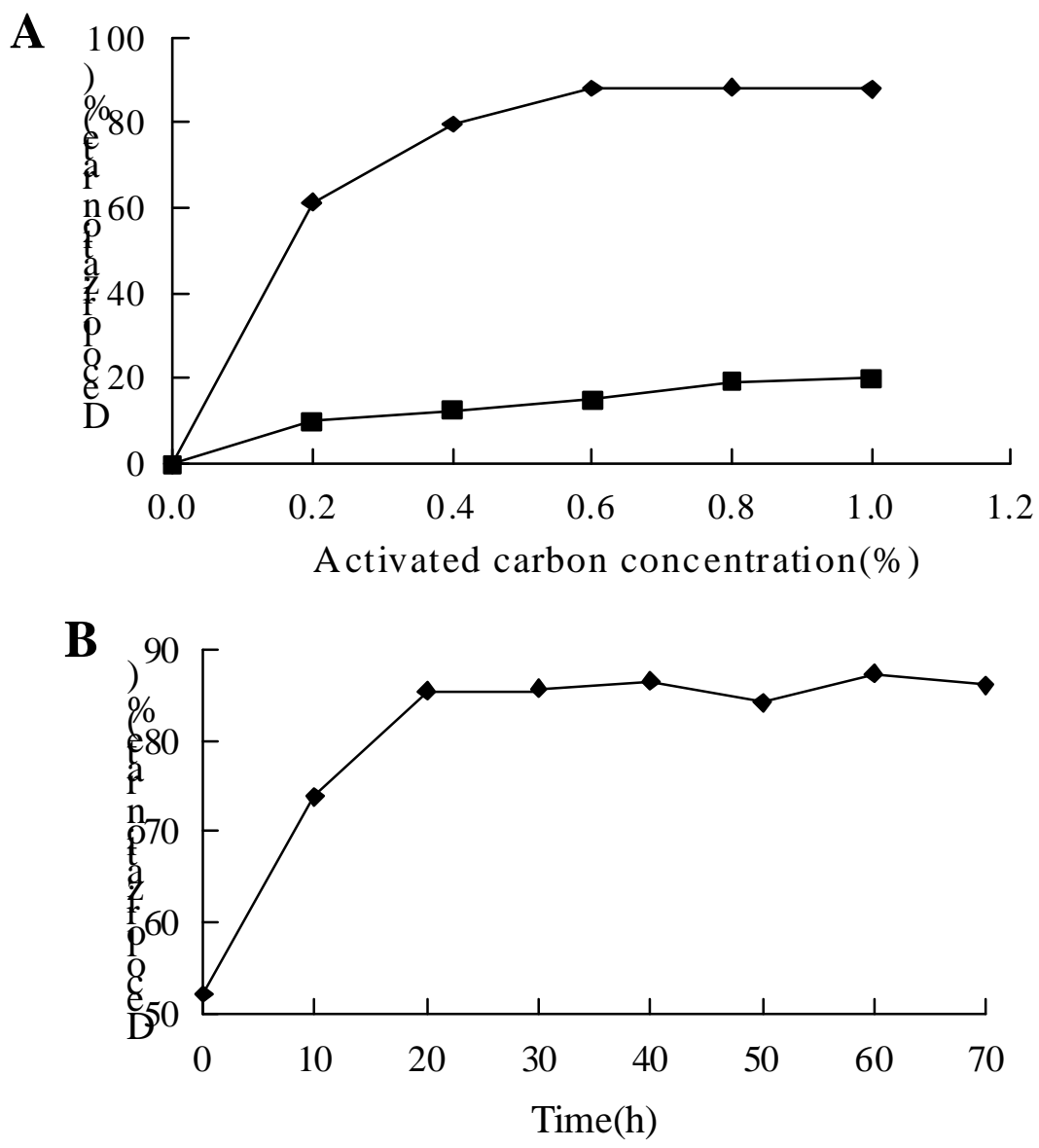

Figure 6: Effect of activated carbon powder and activated carbon granules (A), and effect of shaking time (B) on removal of pigment from fermentation liquid. Note: means powdered activated carbon. - means granular activated carbon

Table 1: Removal of low molecular weight impurities from $y$ - PGA solution by hollow-fiber cartridge

\begin{tabular}{lcccc}
\hline & \multicolumn{2}{c}{ Concentrated liquid } & Filtration fluid \\
\cline { 2 - 5 } Low molecular impurities & $\begin{array}{c}\text { Glutamic } \\
\text { acid } \\
(\mathbf{g} / \mathbf{L})\end{array}$ & $\begin{array}{c}\text { Glucose } \\
(\mathbf{g} / \mathbf{L})\end{array}$ & $\begin{array}{c}\text { Glutamic } \\
\text { acid } \\
(\mathbf{g} / \mathbf{L})\end{array}$ & $\begin{array}{c}\text { Glucose } \\
(\boldsymbol{g} / \mathbf{L})\end{array}$ \\
\hline Before concentration(400mL) & 2 & 12 & - & - \\
Concentrated to $100 \mathrm{~mL}$ & 2 & 9 & 2 & 13 \\
Diluted to 400mL and then concentrated to 100mL & 0 & 3 & 1 & 2 \\
Diluted to 400mL and then concentrated to 100mL & 0 & 0 & 0 & 1 \\
Diluted to 400mL and then concentrated to 50mL & 0 & 0 & 0 & 0 \\
\hline
\end{tabular}

Repeated concentration not only increased the concentration of $y$ - PGA, but also effectively removed low molecular impurities and improved the purity of the $y$ - PGA. The final product was pre-frozen at $-70{ }^{\circ} \mathrm{C}$ for $48 \mathrm{~h}$, and then freeze dried at $-55^{\circ} \mathrm{C}$ for $48 \mathrm{~h}$ (Figure 7 ).

\section{Characteristics of $\mathrm{Y}-\mathrm{PGA}$}

The molecular weight of $\mathrm{y}$ - PGA was $1095 \mathrm{kDa}$ (as determined using GPC), and the poly diversity index (Mw/Mn) was 1.060. The spectrum from UV scan of PGA showed 
absorption peak at $216 \mathrm{~nm}$. There was no absorption peak in the range of $260-280 \mathrm{~nm}$, indicating absence of peptide chain structure in the polymer.
Td (decomposition temperature) was measured with thermal gravimetric analysis (TGA) by heating at a rate of $10{ }^{\circ} \mathrm{C}$ per min. As shown in Figure 8, $\mathrm{Td}$ was $312.92{ }^{\circ} \mathrm{C}$.
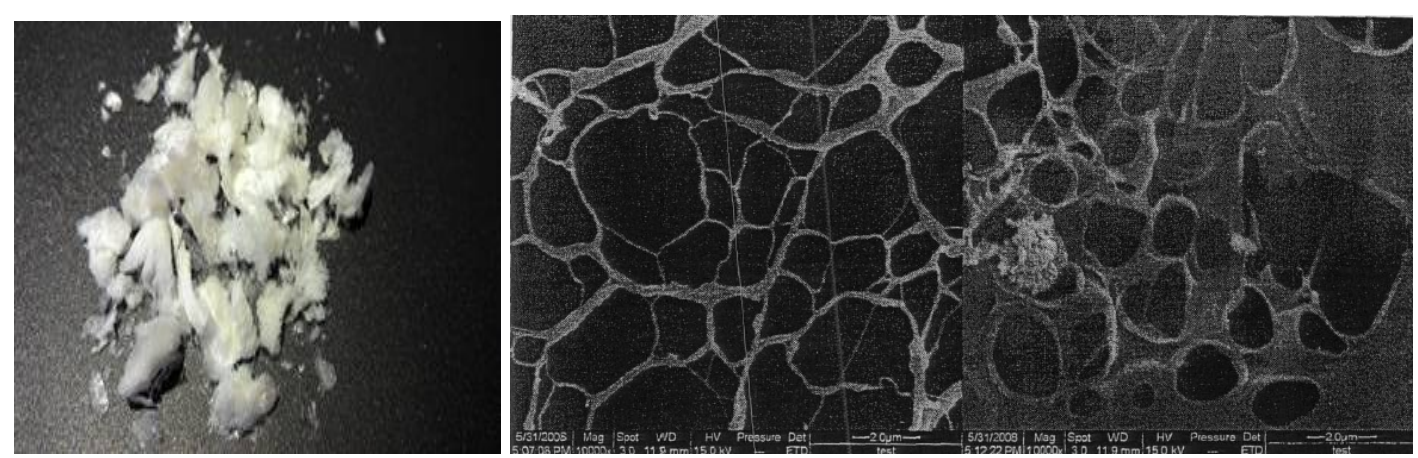

Figure 7: Concentrated solution of $\mathrm{Y}$-PGA pre-frozen at $-70^{\circ} \mathrm{C}$ for $24 \mathrm{~h}$, and freeze-dried at $-55^{\circ} \mathrm{C}$ for $48 \mathrm{~h}$

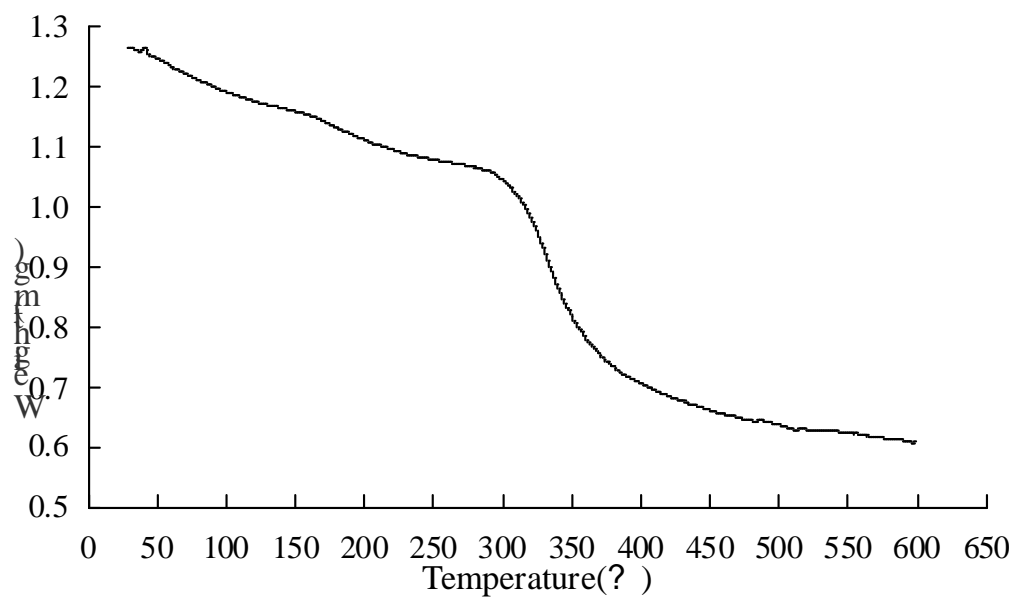

Figure 8: Thermal properties of $\mathrm{Y}-\mathrm{PGA}$

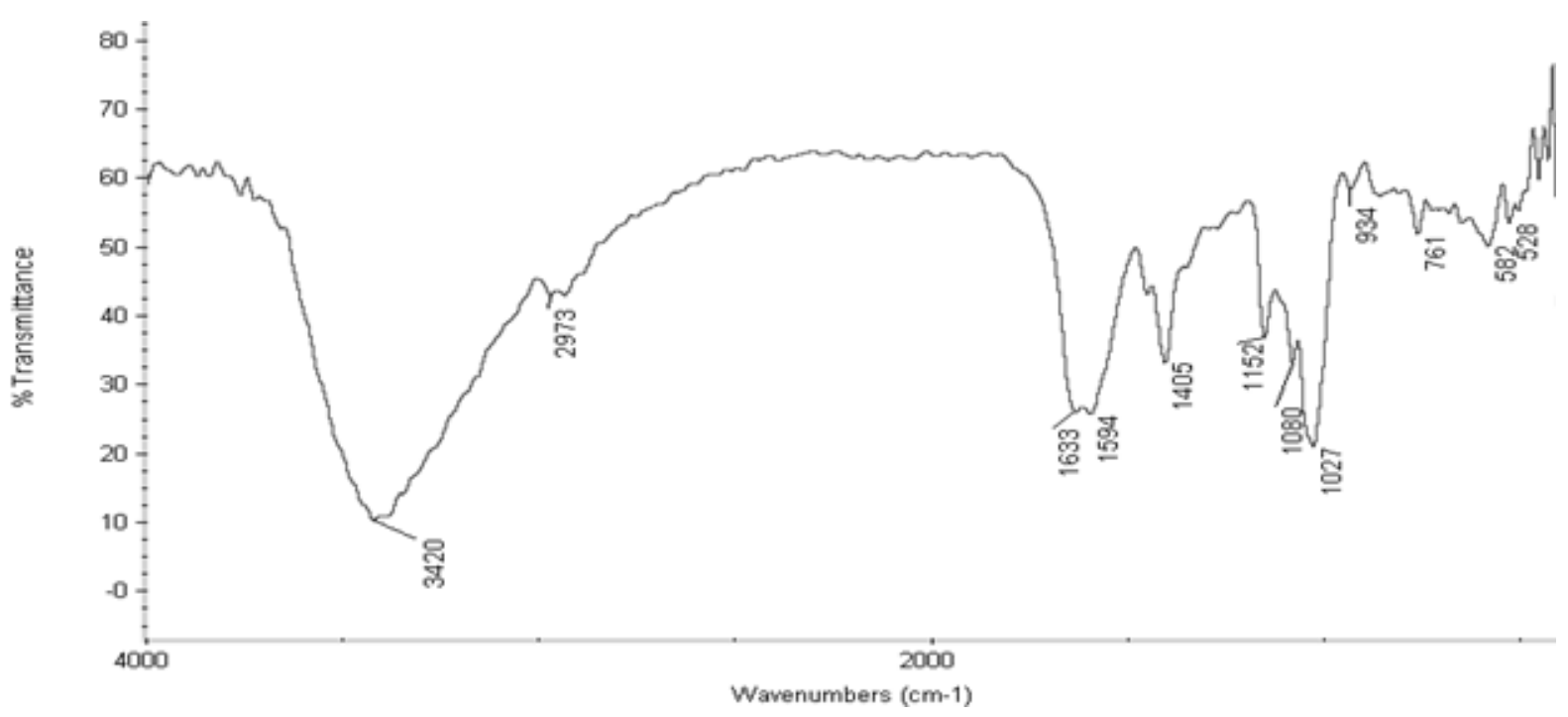

Figure 9: Infrared (FT-IR) absorption spectrum of $\mathrm{y}-\mathrm{PGA}$ in $\mathrm{KBr}$ pellet

Figure 9 shows the infrared spectrum of $y$ - PGA in $\mathrm{KBr}$ pellet: Amide $\mathrm{I}, \mathrm{N}-\mathrm{H}$ bending band at $1633 \mathrm{~cm}^{-1}$; Amide II, stretching band at $1594 \mathrm{~cm}^{-}$ ${ }^{1} ; \mathrm{C}=\mathrm{O}$ symmetric stretching band at $1405 \mathrm{~cm}^{-1}$;
C - N stretching band at $1152 \mathrm{~cm}^{-1} ; \mathrm{N}-\mathrm{H}$ group bending band at $707 \mathrm{~cm}^{-1}$; and $\mathrm{O}-\mathrm{H}$ stretching band at $3420 \mathrm{~cm}^{-1}$. The absorption peak at 3400 - $3450 \mathrm{~cm}^{-1}$ is characteristic of $\mathrm{OH}$ stretching 
from the bound hydroxyl group and adsorbed water molecules. The absorption peaks around $1600-1660 \mathrm{~cm}^{-1}$ and $1390-1450 \mathrm{~cm}^{-1}$ are characteristic of amide groups and $\mathrm{C}=\mathrm{O}$ groups. The strong absorption peaks observed in the range from 1085 to $1165 \mathrm{~cm}^{-1}$ are characteristic of $\mathrm{C}-\mathrm{N}$ groups. The IR spectrum of the $y$-PGA conforms to the presence of carboxyl, hydroxyl, carbonyl and amide groups.

\section{DISCUSSION}

The production of $\mathrm{Y}$ - PGA with Bacillus subtilis 115 was partially associated with cell growth, which is in agreement with results reported earlier [3-5]. The levels of consumption of glutamate and glucose during the fermentation process were about $10 \mathrm{~g} / \mathrm{L}$ and $60 \mathrm{~g} / \mathrm{L}$, respectively. The change of $\mathrm{pH}$ during fermentation was slight, and could be used as a criterion for the normal or not fermentation with the consumption of glucose and glutamic acid.

The first task in the process of refining the $Y$ PGA was to remove the $B$. subtilis 115 cells from culture broth. However, it was necessary to handle the culture broth first in order to make for efficient removal of the cells due to the high viscosity of the fermentation broth containing $\mathrm{Y}$ PGA. After investigated the effects of dilution ratio, temperature and $\mathrm{pH}$ on the viscosity of fermentation broth, it was found that dilution could be used as the most effective pretreatment method, and the cell could be effectively removed by dilution. Because of higher thermal energy of water molecules, the viscosity of $\mathrm{Y}$ PGA solution did not decrease with increasing temperature as expected. Optical Rotatory Dispersion (ORD) studies have shown that strong hydrogen bonds make the $\mathrm{Y}$ - PGA assume a tightly compacted a-helix conformation, resulting in a strong hydrophobic character [6]. However, as $\mathrm{pH}$ increases, the hydrogen bonds are broken, the a-helical conformation changes into a linear random - coil conformation, and the $\mathrm{a}-\mathrm{COOH}$ group ionizes to form a -COO- anion. It was reasoned that the viscosity of culture broth containing $\mathrm{Y}$-PGA would decrease at low $\mathrm{pH}$ due to the reduction of ionized $Y$ - PGA, which would result in less interaction between water and $Y$ - PGA. It has been reported that the zeta potential of cells was reduced with decreases in $\mathrm{pH}$ from 7 to 2 [7]. The cells, which had lost their surface charges at low $\mathrm{pH}$, were aggregated by their interactions. It was also reported in the same studies that separating $\mathrm{y}$ - PGA at low $\mathrm{pH}$ was beneficial on a large - scale, because it resulted in significant lowering of energy cost implications [7]. However, this was not a favorable method for isolating $Y$ - PGA because the polymer chains of $Y$ - PGA might be liberated under acidic conditions, which would result in a decrease in molecular weight of $Y$ - PGA.

Although activated carbon can effectively adsorb the pigment in fermentation broth, it was also found that the longer the contact time of activated carbon with the fermentation fluid containing $Y$ - PGA, the harder it became to separate the activated carbon from $Y$ - PGA. It is likely that the activated carbon was trapped by the high molecular weight $y$ - PGA.

Ultra-filtration not only increased the concentration of $Y$ - PGA, but also effectively removed low molecular impurities and improved the purity of the $Y$ - PGA.

\section{CONCLUSION}

This study demonstrates that the problem of extracting and purifying $\mathrm{y}-\mathrm{PGA}$ from high viscosity fermentation broth has been resolved using the method developed. The viscosity of the fermentation broth can be greatly reduced by dilution so that cells can be effectively removed. Activated carbon decolorization and ultrafiltration improves the purity of $\mathrm{Y}-\mathrm{PGA}$ and lower the cost of extraction and purification of $y-P G A$, thus making it possible to use $\mathrm{Y}-\mathrm{PGA}$ more widely.

\section{DECLARATIONS}

\section{Acknowledgement}

The authors would like to thank all the staff of Key Laboratory of Food Science and Engineering, College of Heilongjiang, as well as all partners for their assistance.

\section{Conflict of Interest}

No conflict of interest associated with this work.

\section{Contribution of Authors}

The authors declare that this work was done by the authors named in this article and all liabilities pertaining to claims relating to the content of this article will be borne by them.

\section{Open Access}

This is an Open Access article that uses a funding model which does not charge readers or their institutions for access and distributed under the terms of the Creative Commons Attribution License (http://creativecommons.org/licenses/by/ 
4.0) and the Budapest Open Access Initiative (http://www.budapestopenaccessinitiative.org/rea d), which permit unrestricted use, distribution, and reproduction in any medium, provided the original work is properly credited.

\section{REFERENCES}

1. Ivanovics G, Bruckner $V$. The chemical nature of the immuno-specific capsule substance of anthrax bacillus. Naturwissenschaften 1937; 25: 250.

2. Shih IL, Van YT. The production of poly-(g-glutamic acid) from microorganisms and its various applications. Bioresour Technol 2001; 79: 207-225.

3. Chen $X$, Chen $S$, Sun $M, Y u$ Z. High yield of poly([gamma]-glutamic acid) from Bacillus subtilis by solid-state fermentation using swine manure as the basis of a solid substrate. Bioresour Technol 2005; 96 : 1872-1879.

4. Chen $X$, Chen S, Sun M, Yu Z. Medium optimization by response surface methodology for poly- $y$-glutamic acid production using dairy manure as the basis of a solid substrate. Appl Microbiol Biotechnol 2005; 69: 390-396.

5. $X u H$, Jing $M$, Li H, Lu D, Ouyang $P$. Efficient production of poly([gamma]-glutamic acid) by newly isolated Bacillus subtilis NX-2. Process Biochem 40: 519-523.

6. Ho G, Ho T, Hsieh K, Su Y, Lin P, Yang J, Yang K, Yang S. $\gamma$-Polyglutamic Acid Produced by Bacillus subtilis (natto): Structural Characteristics, Chemical Properties and Biological Functionalities, J Chinese Chem Soc 2006; 53: 1363-1384

7. Jin Hwan Do, Ho Nam Chang, Sang Yup Lee. Efficient Recovery of $\gamma$-Poly (Glutamic Acid) From Highly Viscous Culture Broth, Biotechnol Bioeng 2001; 76(3): 219-223. 